\title{
Scientific and Technological Links from Samsung On Lithium Batteries and Graphene
}

\author{
Fernando Moreno-Brieva ${ }^{1,2^{*}}$, Carlos Merino-Moreno ${ }^{3}$
}

\begin{abstract}
Lithium and graphene are two substantial raw materials for the manufacture of lithium secondary batteries that can be recharged quickly, whenever a user needs it for the operation of computers, electric vehicles and cell phones, among other products. In this regard, Samsung appears as the world's leading corporation, by observing the technology generation of this type of batteries and the molecule indicated previously, considering its environment and management. For this reason, the study aims to analyze and compare the effects of technological regimes on the technology generation of the leading companies of the Samsung group, as well as their networks, considering patent applications and the types of institutions related, even if there is collaboration between these companies. Our findings show that Samsung's selected companies, related to lithium rechargeable batteries and graphene, are strongly linked to their technological regimes.
\end{abstract}

Keywords: Samsung; technology generation; value chain; lithium; graphene; patent.

Submitted: July $11^{\text {th }}, 2020 /$ Approved: December $14^{\text {th }}, 2020$

\section{Introduction}

Within the framework of a world, in which electric power consumption grows every year due to the greater use of devices related to the digital economy and the growth of vehicles with this type of energy, the interaction between the different economic agents has been facilitated at a global level. Multinational companies have gone from basing their internationalization on vertical integration (by buying companies from different stages of a productive chain to manage a complete process) to vertical specialization (along a chain), through offshoring and outsourcing activities, where they have no core competenciesin a global environment.

Thanks to the exposed background, there is a greater interest in studying the global value chain of lithium batteries, since these objects are lighter than other chemical compounds used in history, they have no memory effect and, consequently, they have longer useful life than other rechargeable batteries (Winter and Brodd, 2004). Specifically, some research has focused on the location of resources and reserves of this metal (Ebensperger et al., 2005; Grosjean et al., 2012); in the differences of its concentrations and the costs to obtain it from rocks, brines or oceans (Grosjean et al., 2012); in derivative products and worldwide projection (Boxall et al., 2018; Stephan et al., 2017; Vikström et al., 2013); in the composition and features of the different types of existing lithium rechargeable batteries (Stephan et al., 2017; U.S. Geological Survey, 2012) ${ }^{1}$; in the generation and technological positioning (Moreno-Brieva and Marín, 2019), among other topics. In the latter case, scholars already know that South Korea is the absolute and extensible technological leader over time, and with strong ties to Germany.

In line with the foregoing, thanks to nanotechnology, graphite can be separated into two-dimensional and transparent molecules, called graphene, which have allowed the creation of more flexible devices and more efficient rechargeable batteries (Geim and Novoselov, 2007; Novoselov et al., 2004), since it is the fastest known electricity conductor; it has an exceptional thermal conductivity; high elasticity, mobility and hardness; and it is one of the lightest chemical compounds; among other characteristics (Yang et al., 2018). For these reasons, some scholars establish that graphene is revolutionizing technology and is key to solving energy crises, water scarcity and environmental pollution (Dhand et al., 2013; Yang et al., 2018).

On the other hand, some studies establish that scientific linkages and, specifically, the technological regimes of patents (either granted or applied), which may be science-based or technology-based (or socalled tech-based), influence economies (Fan et al., 2017). However, there is no knowledge at a corporation level, since in this study is presented for the first time.

Data from the European Patent Office (2019), for the period 2007 -2016 and globally, show that Samsung is the only group that has two companies - Samsung Display Industry (known as Samsung SDI) and Samsung Electronics - among the top four firms that generate the highest number of new technologies related to lithium rechargeable batteries and graphene, respectively, by considering their patent applications and their respective documents. For this reason, it is relevant to analyze and compare the influence of the technological regime on the technology generation of these companies and their connectivity, in relation to the indicated topics, by seeing patent applications and the institution types with which they relate (companies, universities, research centers, state entities), even if there is collaboration between these Samsung companies.

The rest of this paper proceeds as follows: the next section is related to literature review; Section 3 in the methodology employed; Section

${ }^{2}$ They are also called lithium secondary batteries.

(1) Universidad Complutense de Madrid, Madrid, Spain

(2) Universidad Pontificia Comillas, Madrid, Spain

(3) Universidad Autónoma de Madrid, Madrid, Spain

*Corresponding author: fernmo01@ucm.es

ISSN: 0718-2724. (http://jotmi.org)

Journal of Technology Management \& Innovation (c) Universidad Alberto Hurtado, Facultad de Economía y Negocios. 
4 in the results about technology generation of Samsung SDI and Samsung Electronics in relation to lithium rechargeable batteries and graphene; and a discussion of results and our conclusions are drawn in Section 5.

\section{Background literature}

In order to understand this study, it is first necessary to reflect on the concepts of science and technology. According to the Science Council (2009), and in line with Lara Rosano (1998), science is "the pursuit and application of knowledge and understanding of the natural and social world following a systematic methodology based on evidence". This is complemented by the Australian Academy of Science (2019), by expressing that science is composed of discovered knowledge and the process to acquire it, since it incorporates observation and systematized experimentation, which supports that nothing is proven in science but that everything is temporarily accepted until new theories are generated and developed, which allows science to be dynamic. On the other hand, according to Dosi and Nelson (2009), technology is the "human designed means for achieving a particular end" that implies the generation and use of detailed, complex and growing knowledge (Pavitt, 1987). Both science and technology involve the use and resolution of problems in different topics (Echeverría, 2003), which are interconnected through patents and the citation of non-patent literatures that provide scientific linkages, such as dissertations, technical reports, scientific literature, among others (Fan et al., 2017; Glänzel and Meyer, 2003; Meyer, 2000; Motohashi and Tomozawa, 2016).

In connection with the foregoing, the scientific linkages are obtained through the following formula (Equation 1) that relates the citing of non-patent literatures of the patents (applied or granted) with the total number of patents (also, applied or granted, respectively) (Fan et al., 2017).

\section{Degree of scientific linkages $=\frac{C_{N P L}}{P_{\text {total }}}$}

[Equation 1]

Being:

$C_{N P L}=$ count of patent families with citing of non-patent literature

$P_{\text {total }}=$ count of total patent families

Regarding the patents - which involve a legal protection of something new for some years (Griliches, 1990) - although they are not a perfect indicator of innovation, because only some inventions are launched or have consequences in the market, and they do not reflect the inventions of developing countries due to their high cost to keep them protected over time (OECD, 2009). They spread information and reflect the generation of technology and knowledge, especially from developed countries (Fan et al., 2017; Griliches, 1990; Jaffe et al., 1993; Moreno-Brieva and Marín, 2019). In turn, the use of patents allows observing and analyzing the connectivity or alliances of organizations or advanced countries (OECD, 2009). In relation to patent citations, they are related to the total factor productivity and are very informative (Bloom and Van Reenen, 2002), since they allow perceiving the trajectory of one or several patents, and can even be associated with science, thanks to citations of non-patent literatures (Glänzel and Meyer, 2003; Meyer, 2000).

In the same context, special attention should be paid to the technological regimes that are studied by the patents generated and citations of non-patent literatures of them, which in the study Fan et al. (2017) are divided into "science-based" or "technology-based (tech-based). The first term is related to publications and patents with high levels of quality and a high influence level of exogenous variables (Cohen et al., 2000), in which there are innovation systems based on institutions, such as universities and public centers of research, which are more focused on the basic sciences and are not completely close to the markets. The second term is oriented to the knowledge generation within companies and the interaction between them. For its part, the connectivity between technology and scientific studies is not quite solid, and focuses on the application of different techniques, on the technological capabilities of organizations, in which innovations tend to be incremental (Böhme et al., 1978; Gilsing et al., 2011; Nelson and Winter, 1982). In line with the foregoing, Fan et al. (2017) create the technology-science correlation index that allows determining if an economy is "science-based" or "tech-based", although the problem with this index is that the results close to the neutral state are minimized and close to the extremes are maximized, because the index is not linear. In turn, that indicator is not adapted to a group of companies — such as Samsung.

In relation to the networks of universities and companies, the literature indicates that there are basically three ways to generate technology together. First, through the technology transfer from an university to a company; second, thanks to the relationship and collaboration between both types of organizations, based on open communication, trust and respect; third, through a hybrid perspective, in which the barriers and facilitators are compensated (Harmon et al., 1997). An example of an effective means to transfer technology is trough a spin-offs - a new company formed from a parent organization - which achieves its fruits after reaching a certain critical mass (Rogers et al., 2001). In this sense, Fontana et al. (2006) specify that companies that actively select their environment and voluntarily disclose their internal competencies are more inclined to collaborate with academic partners and cooperate more widely. In turn, if this is carried out at the global level, Archibugi and Michie (1995) affirm that one of the stages of technological globalization (called by them as technoglobalism) is the global technological collaboration, in which alliances and partners are created to develop knowhow and innovations from different countries, including governments, research agencies and the academic community, which are classified in collaborations between nonprofit organizations and joint ventures in $\mathrm{R} \& \mathrm{D}$ (basically due to the importance of intensive knowledge and the capability to obtain information especially in the initial stages of the inventions). In spite of the foregoing, in that study university-company relationship is not clear, although it is approached through the triple helix model, which adds the government in this connectivity to generate innovations, within a dynamic perspective (Leydesdorff, 2001). 
On the other hand, about graphene, it is known to be a two-dimensional monocrystalline carbon molecule or a monolayer of carbon atoms, densely packed in a benzene ring structure that can take different forms, called fullerene (Novoselov et al., 2004), which allows the electric charge to be transported thousands of interatomic distances without dispersing (Geim and Novoselov, 2007).

In relation to obtaining graphene, numerous methods are developed and classified as "top-down" and "bottom-up". The first way (in which graphene sheets are formed by separation, cleaving, peeling or exfoliation of graphite) has been used in the production of a few layers because a great investment is necessary to obtain low profits. The second involves several methods, although CVD and epitaxial growth are among the most attractive for the manufacture of large-scale graphene (Dhand et al., 2013). With respect to the value chain of this fullerene, its composition involves the upstream industry of graphite, the CVD graphene preparation method and carbonaceous gas; the mid-stream industry of graphene film, graphene powder, graphene-based compounds; the downstream industry of new energy (for lithium-ion batteries, supercapacitors and solar cells); electronics (for flexible display devices and sensors); the composite materials industry (for electrical conductivity composite materials, heat conductivity composite materials and reinforcement materials); the biomedical industry (for drug carriers, gene therapies, and biological detections); and the environmental protection industry (for seawater desalination and sewage disposals) (Yang et al., 2018).

Among the reasons why lithium secondary batteries are being applied increasingly, are the fact that they are lighter than those of other compounds, they have no memory effect and have a longer lifespan than other rechargeable batteries (Winter and Brodd, 2004). Regarding the value chain of this type of batteries, its origin in obtaining from brines, rocks or seawater stands out (Moreno Brieva, 2015). Although, this last source is practically not used at present due to the high costs caused by the low concentration of lithium it contains (Grosjean et al., 2012). Lithium batteries themselves belong to the third stage of production of this value chain (also called the application stage) and are created by integrating several components (such as cobalt and graphene), which in turn allow the creation of derivative products, for example: electric vehicles, laptops and cell phones (Comisión Chilena del Cobre, 2009; Ebensperger et al., 2005; Moreno-Brieva and Marín, 2019; Stephan et al., 2017). On the other hand, lithium rechargeable batteries can be complemented with sources of clean energy technologies, such as wind and solar, because they can store that type of energy (Lowe et al., 2010; Samsung, 2016).

In a reference to technology generation of lithium rechargeable batteries, according to Moreno-Brieva and Marín (2019), the leading countries are (in descending order of patent applications): South Korea, Japan, the United States, China and Germany. Despite they are almost never linked, except in the case of South Korea and Germany that apparently have some level of alliance related to lithium secondary batteries, although it is not known if this connectivity is by political agreements or by individual efforts of some companies. Notwithstanding the foregoing, in the same study by offsetting the technology generation with international trade, China is the leading country in the global value chain of lithium batteries, since it is the only economy with global advantages in most of its components.

\subsection{About Samsung}

The Samsung group was founded as a grocery trading store in TaeguKorea in 1938, although without taking off abroad (K. Lee and He, 2009). In 1953, thanks to the sugar refining from an affiliate company, it began to have an international presence, but its real takeoff was produced by capital-intensive production and services (Amsden and Hikino, 1994). In the next 35 years, Samsung diversified to: life insurance (1963); newspaper publishing entertainment (1965); hospital administration (1966); paper manufacturing (1967); electronics (1969); petrochemicals, machinery and overseas general trading (1974); real estate (1976); semiconductors and precision machinery (1977); telecommunications and construction (1978); sports entertainment (1982); watchmaking (1983); medical equipment and supplies (1984); data processing (1985); aerospace (1987); and computers (1988); mobile phone system (1992); digital TV (1999); smartphones (2008); among others (Amsden and Hikino, 1994; Samsung, 2016).

There is evidence that the Samsung group is a hierarchical organization (run by the National Pension Service of Korea and, the magnate, Lee Kun Hee), with two central companies that make strategic decisions. Samsung Electronics (with assets of about 339.3 billion dollars in 2018) that is dedicated to the manufacture of cellphones, monitors, tablets, laptops, memory cards, among others; and Samsung Life Insurance (with assets of about 289.3 billion dollars in 2018) that is dedicated to the functions indicated by its own name and to the financial services business. This last company, despite having fewer assets than the Samsung Electronics, owns 8.5\% of it.

In turn, Samsung Electronics has the largest share of two subsidiaries: First, Samsung SDI ${ }^{4}$, which is dedicated to the creation of renewable energy and energy storage systems and is not among the first shareholders of other companies in the Samsung group. Second, Samsung SDS (also called Samsung Data Systems) ${ }^{5}$, which is responsible for the operations of Samsung group systems, is not among the first shareholders of other companies in the grouping. Part of Samsung's SDS property belongs to Samsung C\&T - which is dedicated to the construction sector and is mainly owned by Lee Jae-Yong / Cheil Industries (Nikkei Asian Review, 2019).

Samsung's technological evolution and absorption capacity is based on dynamic capabilities, which according to Song et al. (2016) is "a firm's ability to integrate, build, and reconfigure internal and external competencies to address rapidly changing environments".

\footnotetext{
${ }^{3}$ Mineral extracted and exported almost exclusively from the Democratic Republic of the Congo, which has led to the search for a replacement for this component. ${ }^{4}$ The percentage of the shares held by Samsung Electronics is $19.5 \%$ in October 2019.

${ }^{5}$ The percentage of the shares held by Samsung Electronics is $22.5 \%$ in October 2019.
} 
Specifically, in the case of this Korean group, it has focused on learning of technologies generated by other companies, through formal licenses in the first years and informal ones later; in the technology developed (when other companies did not want to license Samsung); in focusing on the construction of tacit knowledge (thanks to the importance given to investment in R\&D) and in the network of Korean-American scientists and engineers (Linsu, 1997). The foregoing is supported by the governance of the co-opetition (horizontal and vertical) between companies of the Samsung group and by the external co-opetition, which allow generating synergy between the different organizations involved (Song et al., 2016). A successful example of these features is that Samsung Electronics reached Sony in the generation of different technologies in the 1990s (Hyung and Lee, 2010).

Although the Samsung group faced lawsuits against Apple, as a defendant and plaintiff, in different countries around the world (such as the United States, Germany, Japan and South Korea), for several utility and design patents from 2011 to 2019; and it was not the creative group of smartphones, since it was the American firm in 2007.(W. S. Lee et al., 2019; Samuelson, 2017). This Korean group increased its equity from U.S.\$205 billion in 2014 to U.S.\$306 billion in 2018 (current prices), and its net income exceeded U.S.\$22 billion in all years of the period 2014-2018 (Nikkei Asian Review, 20196). Even, Samsung Electronics' share in the smartphone market has evolved positively, because it has remained as the world's leading company, with at least $18 \%$ since the first quarter of 2012 (Statista, 20197).

\section{Methods}

This study is carried out thanks to the data obtained from a set of queries, with keywords searched in the patent application families - of the Global Patent Index belonging to the European Patent Office (2019) from January 30, 2019 to February 28, 2019. Specifically, the period analyzed is from 2007 to 2016, since the first year is when the technology generation of lithium rechargeable batteries begins to grow rapidly, and Samsung starts to invent new technologies with graphene.

Of all the companies in the world, this study focuses on two: Samsung Electronics and Samsung SDI because both companies belong to the same group and are in the top 4 patent applications of graphene, and lithium rechargeable batteries, respectively, at the global level, in the period indicated previously; and also because both companies are from South Korea - the country with the highest number of patent applications and connectivity in relation to the technology generation of this type of batteries.

Thanks to a new index, with the data obtained, it is possible to know the technology regime that both companies belonging to the Samsung group have, their different links around the world and the types of organizations with which they relate.
In the results section presents: First, the properties of the new index to know its characteristics. Second, the technology flows (called evolution of technology or knowledge generation) of graphene, and lithium rechargeable batteries to contextualize the situation of these technological goods at the global level. Finally, the selected applicants (non-inventors) are compared and analyzed, with respect to the countries of origin of the patent applications and the connectivity of both companies of the Samsung group, according to the same technological goods.

\section{Results}

\subsection{The new index and its properties}

The technology-science linear correlation index of a company belonging to a corporation or group of firms (TSLCIC, and as seen in Equation 2) allows knowing if a company is technology-based (when the results are from -100 to the lower limit of zero), science-based (when the results are from the upper limit of zero to 100) or neutral (when the results are equal to zero). Specifically, the first situation arises when the degree of scientific linkages of all the companies in a group (on the right hand of the parenthesis) is higher than the degree of scientific linkages of a specific technology of a company belonging to the same group (on the left hand of the parenthesis). The second situation arises when the degree of scientific linkages of all the companies in a group is lower than the degree of scientific linkages of a specific technology of a company belonging to the same group. Finally, the third situation arises when the degree of scientific linkages of all the companies in a group is equal to the degree of scientific linkages of a specific technology of a company belonging to the same group.

Specifically, the number 100 in the equation is to transform the result into a percentage. This formula is inspired by the TSCI of Fan et al. (2017) although, as this new equation is linear, the distances of the different results are equivalent, a situation that does not occur in the previous one. The TSLCIC formula is as follows:

$$
T S L C I C_{i j}=100\left(\frac{C_{N P L, j i}}{P_{j i}}-\frac{C_{N P L, w}}{P_{w}}\right)
$$

[Equation 2]

Being:

TSLCIC=technology-science linear correlation index of a company belonging to
a corporation
$i=$ company
$j=$ type of technology
$C_{N P L, j i}=$ count of patent application families with citations of non-patent litera-
ture of technology $j$ of the company $i$
$P_{j i}=$ count of patent application families of the technology $j$ of the economy $i$
$C_{N P L, w}=$ count of patent application families with citation of non-patent literatu-
re of all the technologies of the corporation
$P_{w}=$ count of patent application families of all the technologies of the corporation

${ }^{6}$ By considering the following companies of the group: Samsung Electronics, Samsung Life Insurance, Samsung SDI, Samsung C\&T, and Samsung SDS. ${ }^{7}$ The year considered as current is 2019 
The two properties of the new index are presented below and have transverse and temporal dimensions.

\subsubsection{The comparability}

Since the TSLCIC scores allow the cross-company comparison of a corporation. If the result is $\triangle T S L C I C_{ \pm(1-2)}$ indicates that company 1 is more science-oriented than company 2 . If the result is $\triangle$ TSLCIC $_{f(1-2)}$ indicates that company 1 is more technology-oriented than company 2 .

$$
\begin{aligned}
& \text { TSLCIC }_{J(1-2)}=\text { TSLCIC }_{J 1}-\text { TSLCIC }_{J 2} \\
& \operatorname{TSLCIC}_{J(1-2)}=\left\{100\left(\frac{C_{N P L, j 1}}{P_{j 1}}-\frac{C_{N P L, w}}{P_{w}}\right)\right\}-\left\{100\left(\frac{C_{N P L, j 2}}{P_{j 2}}-\frac{C_{N P L, w}}{P_{w}}\right)\right\}
\end{aligned}
$$

[Equation 3]

In addition, given the TSLCIC scores allow the cross-technology comparison of a company. If the result is $\Delta T S L C I C_{\not(1-2)}>0$ indicates that a company is more science-oriented in technology 1 than in technology 2. If the result is $\triangle T S L C I C_{f(1-2)}<0$ indicates that a company is more science-oriented in technology 2 than in technology 1 .

$$
\begin{aligned}
& \operatorname{TSLCIC}_{(1-2) i}=\operatorname{TSLCIC}_{1 i}-\text { TSLCIC }_{2 i} \\
& \operatorname{TSLCIC}_{(1-2) i}=\left\{100\left(\frac{C_{N P L, 1 i}}{P_{1 i}}-\frac{C_{N P L, w}}{P_{w}}\right)\right\}-\left\{100\left(\frac{C_{N P L, 2 i}}{P_{2 i}}-\frac{C_{N P L, w}}{P_{w}}\right)\right\}
\end{aligned}
$$

[Equation 4]

\subsubsection{The temporality}

The TSLCIC index allows comparing the intertemporal results of $t+1$ minus $t$.

$$
\Delta \operatorname{TSLCIC}_{j i(t+1, t)}=\operatorname{TSLCIC}_{j i(t+1)}-\operatorname{TSLCIC}_{j i(t)}
$$

Being:

$t=$ time

\subsection{Global context}

The evolution of the generation of graphene technology, of lithium rechargeable batteries and both together is carried out considering the number of patent application families from 2001 to 2016, because the first year was when graphene-related technology began to be continuously generated in the world. Specifically, Figure 1 shows that more than $95 \%$ of the data variations explain the models. In turn, it is observed that the year 2007 is key in the technological generation of graphene, and lithium rechargeable batteries, since it is when the stagnation of the inventions of these technological goods ends and, consequently, their growth begins, except when both goods are considered together, since its stagnation ends in 2013, i.e. 6 years later. It is interesting to note that the graphene, and lithium rechargeable batteries suffer a second stagnation, which in the first case extends from 2012 to 2013 and in the second one from 2012 to 2014.

In relation to the formulas, despite some scholars express that the growth of these technological goods is exponential. According to data from the European Patent Office (2019), as shown in Figure 1, it is observed that lithium rechargeable batteries, graphene and both technologies grow together polynomially with an $\mathrm{R}^{2}$ over $95 \%$, in the period analyzed. Although, the first good is increasing faster than the second one, because its growth is grade 3. On the other hand, both technological goods together are quantitatively far from the potential of both goods separately.

Figure 1: Evolution of technology generation of graphene, lithium rechargeable batteries and both together, in the period 2001-2016.

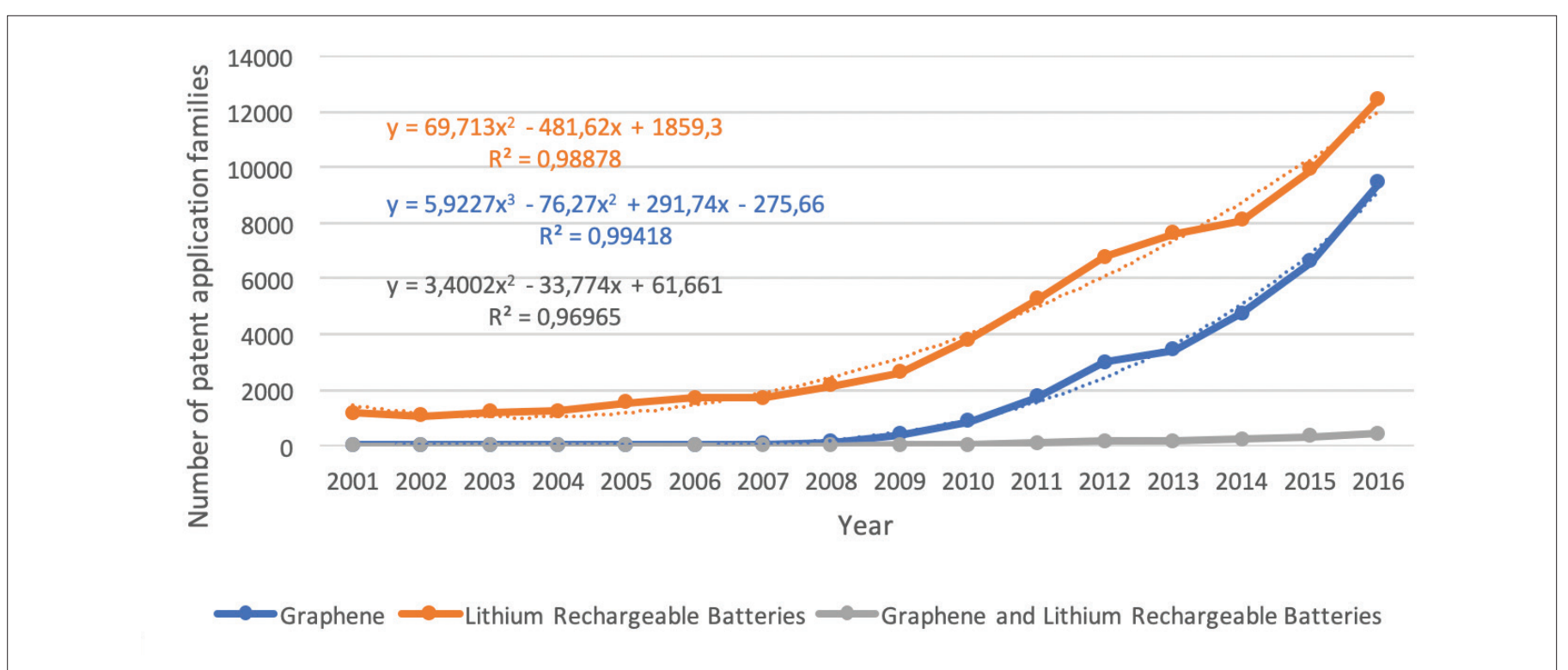

Source: European Patent Office (2019). Own elaboration. 
After observing the evolution of the technological generation of graphene, and lithium rechargeable batteries. The following sections discuss the technology regimes and the collaboration of Samsung SDI and Samsung Electronics in the same technological goods, although since 2007 because it is the year in which Samsung group begins to generate technology with graphene. The last year is still 2016, because the data up to that year is robust.

\subsection{Comparative Analyses}

By comparing the evolution of the number of patent application families of Samsung SDI and Samsung Electronics in relation to lithium rechargeable batteries and graphene (Figure 2), it is observed that: First, Samsung SDI annually generates mostly technology linked to lithium rechargeable batteries, characterized by its high growth from 2011 to 2012 and its subsequent decline until 2016. Second, Samsung
Electronics, with respect to graphene, had a similar curve to that seen in Samsung SDI (in the previous case), although its technology generation was considerably less. Third, Samsung SDI, in relation to graphene, had a lower technology generation than the other company and technological good analyzed. Fourth, Samsung Electronics, regarding the lithium rechargeable batteries, had an almost continuous growth, which allowed this company to overcome the technology generation made with graphene in the same organization.

Regarding the technology regimes of the leading Samsung's companies in relation to graphene, and lithium rechargeable batteries, from 2007 to 2016 (Figure 2), Samsung SDI on both topics is technology-based, while Samsung Electronics is science-based ${ }^{8}$. Although, in both companies, these orientations are sharpened in the case of graphene.

Figure 2: Technology evolution of the main companies of Samsung in relation to graphene and lithium rechargeable batteries, in the period 2007-2016.

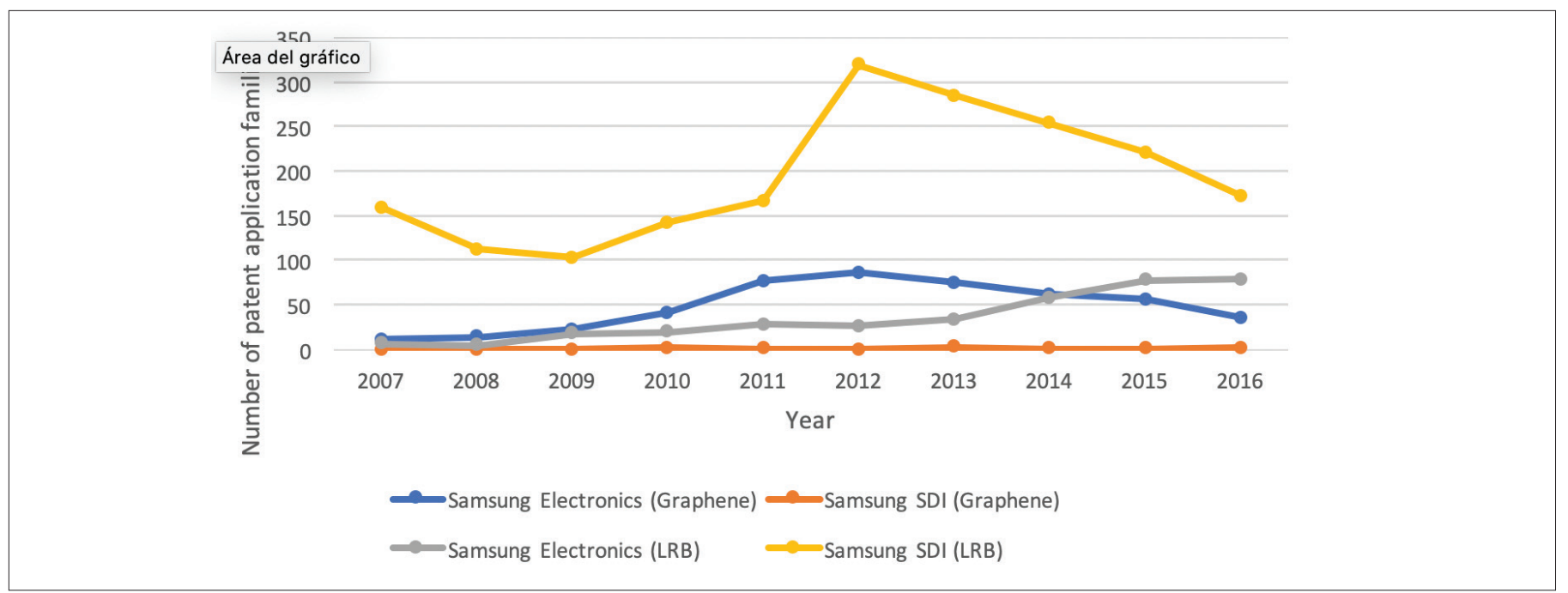

Source: European Patent Office (2019). Own elaboration.

Figure 3: Technology regime of the main Samsung's companies, in relation to graphene and lithium rechargeable batteries, in the period $2007-2016$.

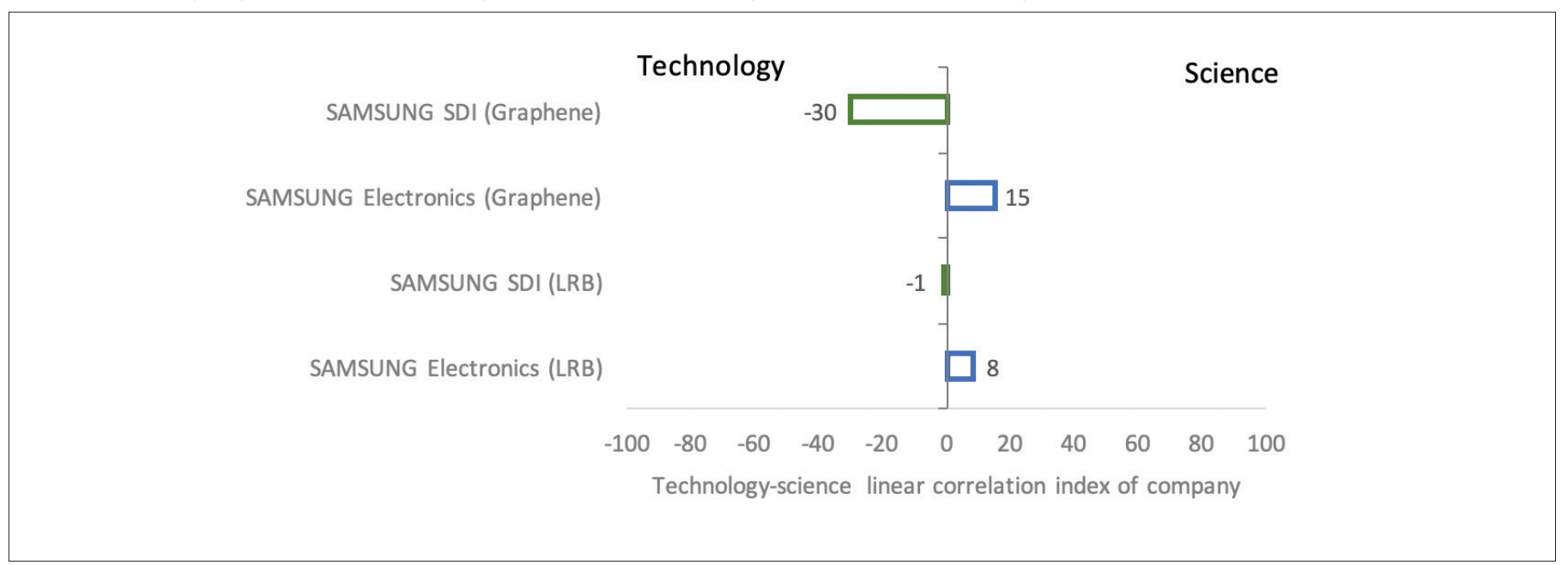

Source: European Patent Office (2019). Own elaboration.

${ }^{8}$ With this information of the orientations (or regimes) of Samsung Electronics and Samsung SDI, it is possible to analyze the results of Figures 6 and 7. 
With regard to the relative connectivity that Samsung Electronics and Samsung SDI have in the technology generation with graphene internationally, from 2007 to 2016 (Figure 4), the first company has $4.3 \%$ of patent applications with applicants from other countries (Japan, the United States and Luxembourg), while the second firm has $11.1 \%$ only with Germany (although Graph B represents only 9 patent applications).

In turn, by comparing the technology generation connectivity of Samsung Electronics with Samsung SDI, in relation to lithium rechargeable batteries, from 2007 to 2016 (Figure 5), the first company is connected at $5.8 \%$ with applicants from other countries (Japan, the United States and China), and the second company at $12.8 \%$ with applicants from other countries (Germany, Japan, the United States and Russia).
By comparing Figures 4 and 5, Samsung Electronics generates technology with graphene, and lithium rechargeable batteries at a percentage less than or equal to 5\% with Japan and the United States. In turn, it generates technology in less than $1 \%$ with Luxembourg in relation to the two-dimensional carbon molecule, and with China regarding lithium secondary batteries. In line with the foregoing, Samsung SDI applies for patents on both components with Germany at around 11\%; in the case of lithium rechargeable batteries, it is also connected to Japan, the United States and Russia by $1.2 \%$, while in graphene, it is not additionally linked to another economy.

Figure 4: Relative global connectivity of both Samsung's companies in the technology generation of graphene, in the period 2007-2016.
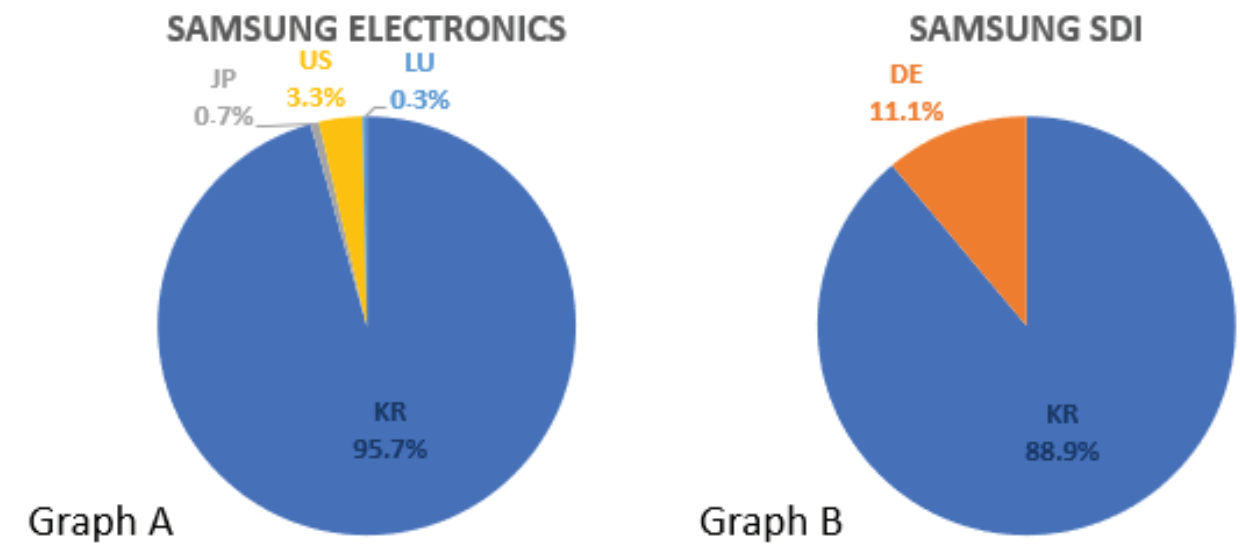

Note: In Graph B, the total patent applications are 9. Korea’s patent applications reflect the required individually or with other organizations in the country. Source: European Patent Office (2019). Own elaboration.

Figure 5: Relative global connectivity of both Samsung's companies in the technology generation of lithium rechargeable batteries, in the period $2007-2016$.
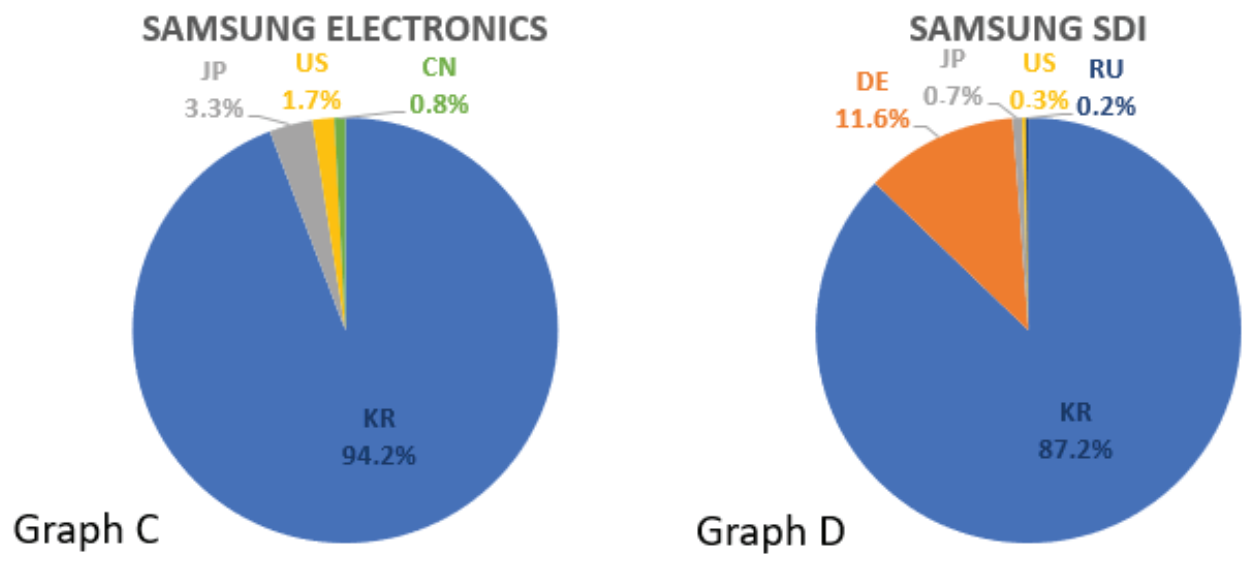

Note: Korea's patent applications reflect the required individually or with other organizations in the country.

Source: European Patent Office (2019). Own elaboration. 
Regarding the technology generation and the connectivity of Samsung Electronics and Samsung SDI, in relation to graphene at the institution level, in the period 2007-2016 (Figure 6), it is observed that the first company applies to almost 33 times more patent than the second one. In turn, both organizations together are related to universities in $80 \%$ and companies in $20 \%$. Although, Samsung Electronics is connected to 9 institutions (8 universities or similar) and Samsung SDI to a single firm (Robert Bosch GMBH) ${ }^{9}$. In line with the foregoing, both companies of the Samsung group, by considering the distribution of patent applications, are in $91.07 \%$ connected to universities or similar and $8.93 \%$ with other companies (including Samsung Corning Precision Materials belonging to the same group), in spite of these numbers are almost exclusively from Samsung Electronics. On the other hand, it is observed that there is no connectivity between Samsung Electronics and Samsung SDI, and only a systematization can be deduced in the link between Samsung Electronics and Sungkyunkwan University, since there are 31 patent applications between both organizations on this topic - supported by the website of this university that establishes that there is a formal alliance since 1996 (Sungkyunkwan University, 2019).

In a reference to the technology generation and connectivity of Samsung Electronics and Samsung SDI, regarding the lithium rechargeable batteries at the institutional level, in the period 2007-2016 (Figure 7), it is observed that the second company applies approximately 5.6 times to more patents than the first one. In turn, both organizations together are related to universities or similar in $68.75 \%$ of the time and with companies in $31.25 \%$, although Samsung Electronics is connected to 13 institutions (11 universities or similar) and Samsung SDI to 6 firms. In line with the foregoing, both companies of the Samsung group, by considering the distribution of patent applications, are connected in $68.15 \%$ with universities or similar, in $8.60 \%$ with other companies (including Samsung Corning Precision Materials and Samsung Fine Chemicals, belonging to the same group), and in $23.25 \%$ among them. Specifically, for the previous, a systematized link between Samsung SDI and Samsung Electronics, and Samsung SDI and Bosch is observed because they jointly request a large number of patent applications. The first case, it is probably due to the high participation in shares of the first company in the second one; while the second case, because there was a joint venture between the two companies from 2008 to 2012.

By comparing Figures 6 and 7, it can be deduced that while Samsung Electronics, both in graphene and lithium rechargeable batteries, is connected to organizations linked to science (such as universities or similar), Samsung SDI is connected only to other companies in the indicated period. This explains that possibly the high connectivity between Samsung SDI and Samsung Electronics in lithium rechargeable batteries is due to the fact that the second company has dynamic capabilities in basic sciences related to raw materials such as graphene, which allows the batteries to recharge quickly and, consequently, improve the quality of the batteries purchased by Samsung Electronics from Samsung SDI — which means approximately $50 \%$ of the revenue of the latter company (K. Lee and He, 2009).

Figure 6: Technology generation and connectivity of Samsung Electronics and SDI, related to graphene, in the period 2007-2016.

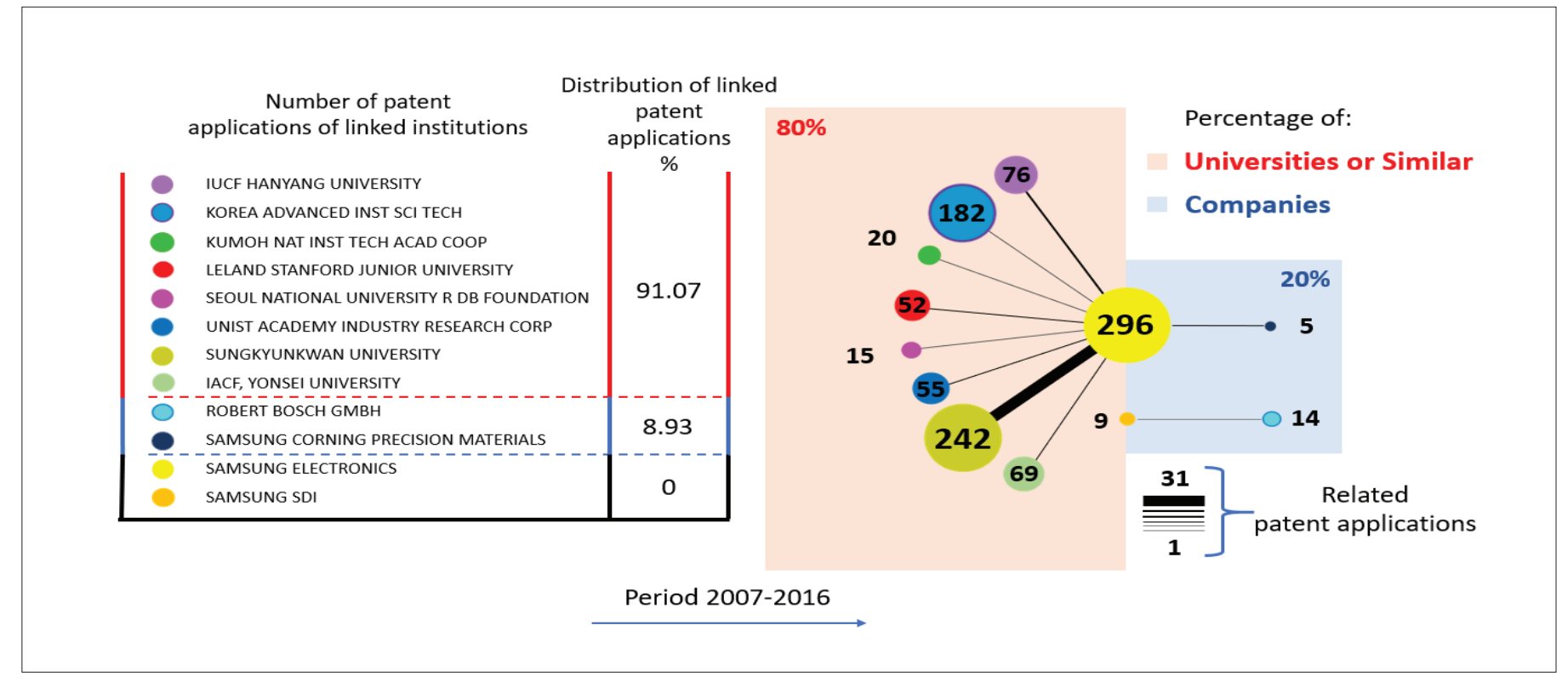

Source: European Patent Office (2019). Own elaboration.

${ }^{9}$ Company founded by Robert Bosch when the "Workshop for Precision Mechanics and Electrical Engineering" was held in Stuttgart, in 1886 . Today, it is in approximately 60 countries around the world. This firm is dedicated to the production of engineering goods and services (Bosch, 2019). 
Figure 7: Technology generation and connectivity of Samsung Electronics and SDI, related to lithium rechargeable batteries, in the period 2007-2016.

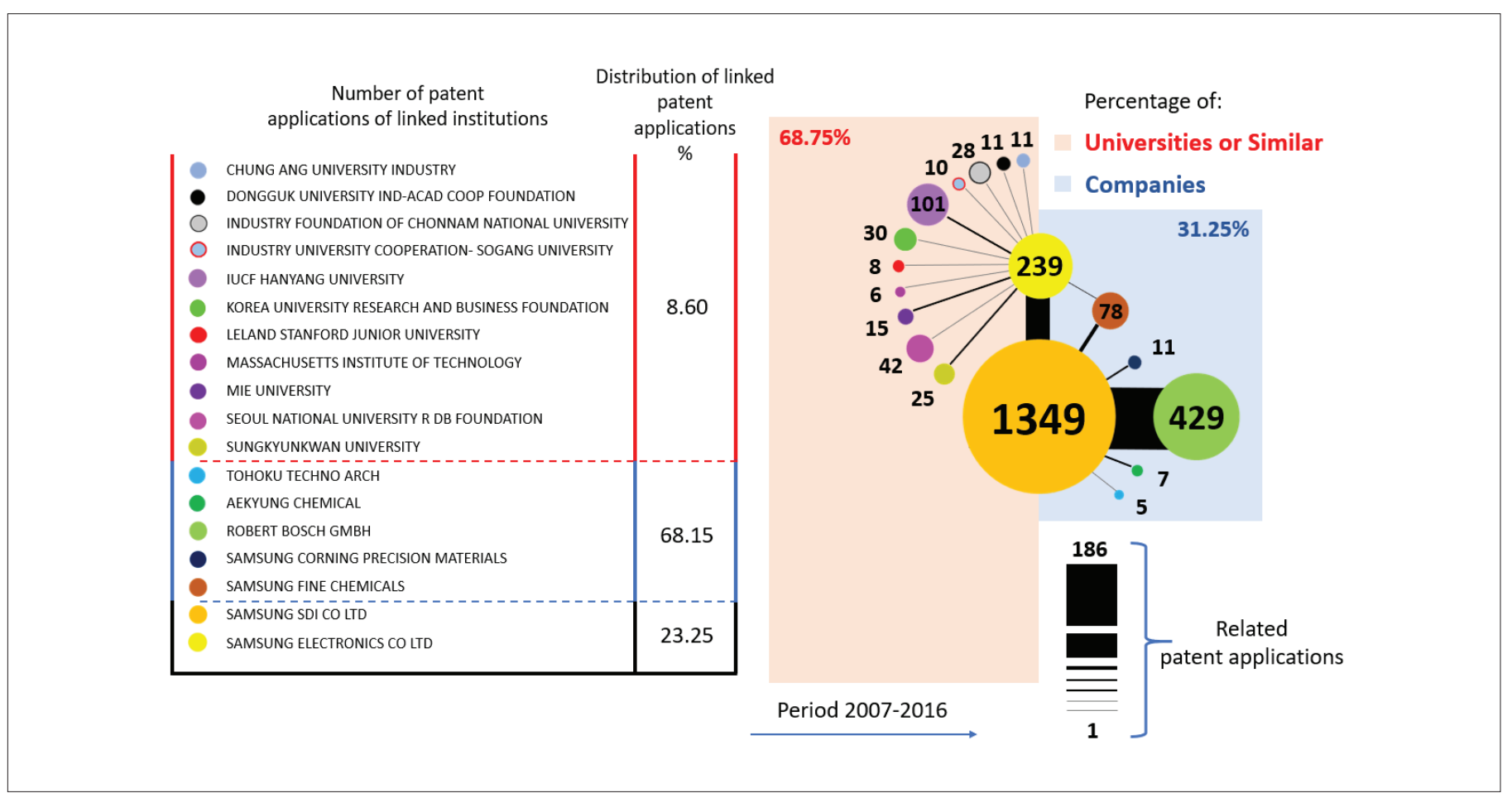

Source: European Patent Office (2019). Own elaboration.

After considering the review of the literature, methodology and results. The discussion and conclusions of the study are presented below.

\section{Discussion and Conclusions}

This research allows us to know that the technology generation of graphene, and lithium rechargeable batteries have a polynomial growth of 3 degrees for the molecule and 2 degrees for batteries, in the period 2001-2016. However, in the case of the main companies of the Samsung group, regarding the patent applications of these technological goods, the evolution has been different since 2012, because the technology generation of lithium rechargeable batteries decreased in the case of Samsung SDI for reasons that indicate that the company was affected by the term of the joint venture that it had with Bosch since 2008, and because Samsung Electronics has given greater importance to its technological innovation capabilities to better relate these batteries to topics such as semiconductors, digital media, telecommunications networks, among others. In turn, the patent applications of Samsung Electronics, related to graphene, declined since 2012, because it was possibly time to slowly advance the benefits and applications with this molecule, among several reasons, to carry out applied studies, since the company was in a period of great uncertainty and might need liquidity to face and pay the costs of legal claims effectuated by Apple, for the improper use of the features of applications and devices, which are protected by industrial property rights.
Regarding the technology regimes, as happened at the country level in the study by Fan et al. (2017), it can also be induced that the Samsung group is notoriously influenced by them to carry out connections with other organizations in matters related to the technology generation, although generally only for individual projects, as occurs throughout the global value chain of lithium batteries, in which countries operate with other economies on very specific occasions.

In line with the foregoing, specifically, this study shows that the Samsung group is linked to universities or similar institutions, when the technology generation is science-based; and to companies, when it is technology-based. In the first case, mainly thanks to the connectivity of Samsung Electronics with Korean organizations. While in the latter case, by the joint venture between Samsung SDI and Bosch, which shows that the link between South Korea and Germany in the global value chain of lithium batteries — seen in Moreno-Brieva and Marin (2019) - is not due to the fact that there is an agreement between both countries, which has been maintained for a long time, but because it is the result of an alliance between two companies that only lasted 4 years (2018-2012), which represents approximately $87 \%$ of patent applications linked between both countries, in relation to lithium rechargeable batteries for more than a century. ${ }^{1}$

As a limitation, this type of study is limited to the institutions that generally apply for patents and which coincidentally tend to be from

${ }^{10} 115$ years is the time analyzed by Moreno-Brieva, F. and Marin, R. (2019). 
developed countries or from China. On the other hand, this research opens a method to analyze the influence of technological regimes on the real connectivity of the technological generation of this or other global or regional value chains (even at the level of the International Patent Classification), through the analysis of other business groups, universities or institutions. Even, positioning studies and possible alliances or confrontations in terms of technological generation can be carried out to understand the dynamics in which the institutions studied are inserted.

\section{References}

Amsden, A. H. and Hikino, T. (1994). Project execution capability, organizational know-how and conglomerate corporate growth in late industrialization. Industrial and Corporate Change, 3(1), 111-147. https://doi.org/10.1093/icc/3.1.111

Archibugi, D. and Michie, J. (1995). The globalisation of technology: a new taxonomy. Cambridge Journal of Economics, (June 2014). https:// doi.org/10.1093/oxfordjournals.cje.a035299

Australian Academy of Science. (2019). What is science? Retrieved September 17, 2019, from https://www.science.org.au/curious/ everything-else/what-science

Bloom, N. and Van Reenen, J. (2002). Patents, real options and firm performance. The Economic Journal, 112(478), C97-C116. https:// doi.org/10.1111/1468-0297.00022

Böhme, G., Van Den Daele, W., and Krohn, W. (1978). The "Scientification" of Technology. Dordrecht: Springer: The Dynamics of Science and Technology.

Bosch. (2019). Home. Retrieved from https://www.bosch.com/

Boxall, N. J., King, S., Cheng, K. Y., Gumulya, Y., Bruckard, W., and Kaksonen, A. H. (2018). Urban mining of lithium-ion batteries in Australia: Current state and future trends. Minerals Engineering, 128(August), 45-55. https://doi.org/10.1016/j.mineng.2018.08.030

Cohen, W. M., Nelson, R. R., and Walsh, J. P. (2000). Protecting their intellectual assets: Appropriability conditions and why U.S. manufacturing firmspatent (or not) (No. 7552). Cambridge.

Comisión Chilena del Cobre. (2009). Antecedentes para una Política Pública en Minerales Estratégicos : Litio. Comision chilena del cobre.

Dhand, V., Rhee, K. Y., Ju Kim, H., and Ho Jung, D. (2013). A Comprehensive Review of Graphene Nanocomposites: Research Status and Trends. Journal of Nanomaterials, 2013, 1-14. https://doi. org/10.1155/2013/763953

Dosi, G. and Nelson, R. R. (2009). Technical Change and Industrial Dynamics as Evolutionary Processes (2009/07).
Ebensperger, A., Maxwell, P., and Moscoso, C. (2005). The lithium industry: Its recent evolution and future prospects. Resources Policy, 30(3), 218-231. https://doi.org/10.1016/j.resourpol.2005.09.001

Echeverría, J. (2003). The techno-scientific revolution (Spanish). México D.F.: Fondo de Cultura Económica.

European Patent Office. (2019). Global Patent Index. Retrieved from https://www.epo.org/searching-for-patents/technical/espacenet/gpi_ de.html\#tab-1

Fan, X., Liu, W., and Zhu, G. (2017). Scientific linkage and technological innovation capabilities: international comparisons of patenting in the solar energy industry. Scientometrics, 111(1), 117-138. https:// doi.org/10.1007/s11192-017-2274-5

Fontana, R., Geuna, A., and Matt, M. (2006). Factors affecting university-industry $\mathrm{R}$ and $\mathrm{D}$ projects: The importance of searching, screening and signalling. Research Policy, 35(2), 309-323. https://doi. org/10.1016/j.respol.2005.12.001

Geim, A. K. and Novoselov, K. S. (2007). The rise of graphene. Nature Materials, 6, 183-191. https://doi.org/https://doi.org/10.1038/nmat1849

Gilsing, V., Bekkers, R., Bodas Freitas, I. M., and Van Der Steen, M. (2011). Differences in technology transfer between science-based and development-based industries: Transfer mechanisms and barriers. Technovation, 31(12), 638-647. https://doi.org/10.1016/j.technovation.2011.06.009

Glänzel, W. and Meyer, M. (2003). Patents cited in the scientific literature: An exploratory study of "reverse" citation relations. Scientometrics, 58(2), 415-428. https://doi.org/10.1023/A:1026248929668

Griliches, Z. (1990). Patent Statistics as Economic Indicators: A Survey. Journal of Economic Literature, 28(4), 1661-1707. Retrieved from https://www.jstor.org/stable/2727442

Grosjean, C., Herrera Miranda, P., Perrin, M., and Poggi, P. (2012). Assessment of world lithium resources and consequences of their geographic distribution on the expected development of the electric vehicle industry. Renewable and Sustainable Energy Reviews, 16(3), 1735-1744. https://doi.org/10.1016/j.rser.2011.11.023

Harmon, B., Ardishvili, A., Cardozo, R. N., Elder, T., Leuthold, J., Parshall, J., ... Smith, D. (1997). Mapping the university technology transfer process. Journal of Business Venturing. https://doi.org/10.1016/ S0883-9026(96)00064-X

Hyung, S. and Lee, K. (2010). Samsung 's catch-up with Sony : an analysis using US patent data. Journal of the Asia Pacific Economy, 15(3), 271-287. https://doi.org/10.1080/13547860.2010.494907

Jaffe, A. B., Trajtenberg, M., and Henderson, R. (1993). Geographic Localization of Knowledge spillovers as evidenced by patent citations. The Quarterly Journal of Economics, 108(3), 577-598. https:// doi.org/10.1111/j.1467-8276.2008.01144.x 
Lara Rosano, F. (1998). Technology: concepts, problems, perspectives (Spanish). Madrid: Siglo Veintiuno de España Editores.

Lee, K. and He, X. (2009). The capability of the Samsung group in project execution and vertical integration: Created in Korea, replicated in China. Asian Business and Management, 8(3), 277-299. https://doi. org/10.1057/abm.2009.9

Lee, W. S., Lee, M. K., Kang, S., and Yoo, J. W. (2019). The SamsungApple patent war: Socio-cultural comparative study of news frames in a business conflict issue. International Communication Gazette, 81(1), 46-65. https://doi.org/10.1177/1748048518767789

Leydesdorff, L. (2001). Knowledge-Based Innovation Systems and the Model of a Triple Helix of University-Industry-Government Relations. In New Economic Windows: New Paradigms for the New Millennium (pp. 1-19). Salerno. Retrieved from http://arxiv.org/abs/1001.1308

Linsu, K. (1997). The dynamics of Samsung's technological learning in semiconductors. California Management Review, 39(3), 86-100.

Lowe, M., Tokuoka, S., Tali, T., and Gereffi, G. (2010). Lithium-ion Batteries for Hybrid and All-Electric Vehicles: the U.S. Value Chain. Center on Globalization, Governance \& Competitiveness., 1(October), 1-77. https://doi.org/10.13140/RG.2.1.1421.0324

Meyer, M. (2000). Does science push technology? Patents citing scientific literature. Research Policy, 29(3), 409-434. https://doi. org/10.1016/S0048-7333(99)00040-2

Moreno-Brieva, F. and Marín, R. (2019). Technology generation and international collaboration in the Global Value Chain of Lithium Batteries. Resources, Conservation and Recycling, 146. https://doi. org/10.1016/j.resconrec.2019.03.026

Moreno Brieva, F. J. (2015). Cadena De Valor Global Del Litio: Países E Ingresos Nacionales Brutos (2015/20 No. 20). Madrid. Retrieved from http://www.uam.es/docencia/degin/catedra/

Motohashi, K. and Tomozawa, T. (2016). Differences in science based innovation by technology life cycles: the case of solar cell technology. Journal of Technology Management and Innovation, 72(1-3), 5-18.

Nelson, R. R. and Winter, S. G. (1982). An evolutionary theory of economic change. Cambridge MA Belknap (Vol. 93). https://doi. org/10.2307/2232409

Nikkei Asian Review. (2019). Nikkei Asian Review. Retrieved from https://asia.nikkei.com/

Novoselov, K. S., Geim, A. K., Morozov, S. V., Jiang, D., Zhang, Y., Dubonos, S. V., ... Firsov, A. A. (2004). Electric Field Effect in Atomically Thin Carbon Films Supplementary. Science (Vol. 5). https://doi. org/10.1126/science.aab1343

OECD. (2009). OECD Patent Statistics Manual. https://doi. org/10.1787/9789264056442-en
Pavitt, K. (1987). The objectives of technology policy. Science and Public Policy, 14(4), 182-188.

Rogers, E. M., Takegami, S., and Yin, J. (2001). Lessons learned about technology transfer. Technovation, 21, 253-261.

Samsung. (2016). History. Retrieved October 10, 2019, from https:// sgsg.samsung.com/main/newpage.php?f_id=samsung_history

Samuelson, P. (2017). Supreme court on design patent damages in Samsung v. Apple. Communications of the ACM, 60(3), 26-28. https:// doi.org/10.1145/3041043

Science Council. (2009). Our definition of science. Retrieved September 17, 2019, from https://sciencecouncil.org/about-science/ourdefinition-of-science/

Song, J., Lee, K., and Khanna, T. (2016). Dynamic capabilities at samsung: Optimizing internal co-opetition. California Management Review, 58(4), 118-140. https://doi.org/10.1525/cmr.2016.58.4.118

Statista. (2019). Global market share held by leading smartphone vendors from 4th quarter 2009 to 2nd quarter 2019. Retrieved October 11, 2019, from https://www.statista.com/statistics/271496/ global-market-share-held-by-smartphone-vendors-since-4th-quarter-2009/

Stephan, A., Schmidt, T. S., Bening, C., and Hoffmann, V. H. (2017). The sectoral configuration of technological innovation systems: Patterns of knowledge development and diffusion in the lithium-ion battery technology in Japan. Research Policy, 46, 709-723. https://doi. org/10.1016/j.respol.2017.01.009

Sungkyunkwan University. (2019). The Cradle of Korean Higher Education, Sungkyunkwan University. Retrieved October 8, 2019, from https://www.skku.edu/eng/About/s620/sub02_01.do

U.S. Geological Survey. (2012). Lithium use in batteries: U.S. Geological Survey Circular 1371. U.S. Geological Survey Circular (Vol. 1371). Retrieved from http://pubs.usgs.gov/circ/1371/

Vikström, H., Davidsson, S., and Höök, M. (2013). Lithium availability and future production outlooks. Applied Energy, 110, 252-266. https://doi.org/10.1016/j.apenergy.2013.04.005

Winter, M. and Brodd, R. J. (2004). What are batteries, fuel cells, and supercapacitors? Chemical Reviews, 104(10), 4245-4269. https://doi. org/10.1021/cr020730k

Yang, X., Yu, X., and Liu, X. (2018). Obtaining a sustainable competitive advantage from patent information: A patent analysis of the graphene industry. Sustainability (Switzerland), 10(12). https://doi. org/10.3390/su10124800

\section{Declaration of Interest:}

The authors declare that they have no conflict of interest. 
